\title{
The reciprocal influences of asthma and obesity on lung function testing, AHR and airway inflammation in prepubertal children.
}

\begin{tabular}{|c|c|}
\hline Journal: & Pediatric Pulmonology \\
\hline Manuscript ID: & PPUL-09-0317.R1 \\
\hline Wiley - Manuscript type: & Original Article \\
\hline $\begin{array}{l}\text { Date Submitted by the } \\
\text { Author: }\end{array}$ & 06-Mar-2010 \\
\hline Complete List of Authors: & $\begin{array}{l}\text { Consilvio, Nicola; University G. D'Annunzio, Department of } \\
\text { Paediatrics } \\
\text { Di Pillo, Sabrina; University G. D'Annunzio, Department of } \\
\text { Paediatrics } \\
\text { Verini, Marcello; University G. D'Annunzio, Department of } \\
\text { Paediatrics } \\
\text { de Giorgis, Tommaso; University G. D'Annunzio, Department of } \\
\text { Paediatrics } \\
\text { Cingolani, Anna; University G. D'Annunzio, Department of } \\
\text { Paediatrics } \\
\text { Chiavaroli, Valentina; University G. D'Annunzio, Department of } \\
\text { Paediatrics } \\
\text { Chiarelli, Francesco; University G. D'Annunzio, Department of } \\
\text { Paediatrics } \\
\text { Mohn, Angelika; University G. D'Annunzio, Department of } \\
\text { Paediatrics }\end{array}$ \\
\hline Keywords: & $\begin{array}{l}\text { Childhood Asthma, Obesity, Fractional exhaled Nitric Oxide, Lung } \\
\text { Function Testing, Airways Hyperresponsiveness }\end{array}$ \\
\hline
\end{tabular}

\section{S ScholaroNE" \\ Manuscript Central}




\section{The reciprocal influences of asthma and obesity on lung function testing, AHR and airway inflammation in prepubertal children.}

Nicola P. Consilvio, MD, Sabrina Di Pillo, MD, Marcello Verini, MD, Tommaso de Giorgis, MD, Anna Cingolani, MD; Valentina Chiavaroli, MD, Francesco Chiarelli, PhD; Angelika Mohn, MD.

Department of Pediatrics, University of Chieti, Chieti, Italy.

Short title: Impact of asthma and obesity on lung function testing.

Word count: 3223

Funding: none

Conflict of Interest: none

Keywords: Obesity, Asthma, Fractional exhaled Nitric Oxide, Lung Function Testing, Airways Hyperresponsiveness.

Correspondence:

Angelika Mohn

Department of Pediatrics

University of Chieti

Via Dei Vestini 5

66100 Chieti

Tel +390871358827

Fax +390871584731

Emailamohn@unich.it 


\section{SUMMARY}

Although asthma and obesity are among the major chronic disorders their reciprocal or independent influences on lung function testing, airways hyperresponsiveness (AHR) and bronchial inflammation has not been completely elucidated.

In 118 pre-pubertal Caucasian children anthropometric measurements functional respiratory parameters (flow/volume curves at baseline and after 6-Minute Walk Test [6MWT]) together with bronchial inflammatory index (FeNO) were assessed. The study population was divided into four groups according to BMI and the presence or absence of asthma: Obese asthmatic $(\boldsymbol{O b} \boldsymbol{A})$ Normalweight asthmatic $(\boldsymbol{N w \boldsymbol { A }})$, Obese non asthmatic $(\boldsymbol{O b})$, non-asthmatic Normal-weight children $(\boldsymbol{N w})$.

Baseline PEF and $\mathrm{MEF}_{75}$ (\%-expected) were significantly different across the four groups with significantly lower values of $\mathrm{MEF}_{75}$ in $\mathrm{ObA}$ and $\mathrm{Ob}$ children when compared to $\mathrm{Nw}$ children $(p=0.004$ and $p=0.0001$, respectively) and this independent role of obesity on upper respiratory flows was confirmed by multiple analysis of covariance.

After 6 MWT respiratory parameters decreased only in ObA and NwA children and 12 children presented a positive fall in $\mathrm{FEV}_{1}$, in contrast no changes of respiratory function testing were detected in $\mathrm{Ob}$ and $\mathrm{Nw}$ children, and only $2 \mathrm{Ob}$ children presented a significant fall in $\mathrm{FEV}_{1}$.

FeNO analysis demonstrated significantly higher values in ObA and NwA children when compared to $\mathrm{Ob}(p=0.008$ and $p=0.0002$, respectively) and $\mathrm{Nw}$ children $(p=0.0001$ and $p=0.0003$, respectively), although a significant difference was found between $\mathrm{Ob}$ and $\mathrm{Nw}$ children $(p=0.0004)$. Multiple analysis of covariance confirmed an independent role of asthma on this parameter.

In conclusion while AHR and airway inflammation are clearly associated with an asthmatic status, obesity seems to induce reduction of upper airways flows associated with a certain degree of pro-inflammatory changes. 


\section{INTRODUCTION}

Over several decades the prevalence of obesity has steadily increased reaching epidemic proportions. Current estimates of childhood obesity coming from the National Health and Nutrition Examination Survey (NHANES) revealed an increase from $13.8 \%$ in $1999-2000$ to $16.0 \%$ in 2003 2004 for American females and from $14.0 \%$ to $18.2 \%$ in American males subjects. ${ }^{1}$ In Europe, Italy together with other Mediterranean countries explicates the highest rate of obesity in children aged between 7 and 11 years, reaching almost $17 \% .^{2}$ This has been accompanied by a similar rise in the rates of asthma. In fact, the CDC National Surveillance for Asthma revealed that its prevalence in children has risen from $3.5 \%$ to $7.5 \%$ over a period ranging from 2001-2003. ${ }^{3}$ Similarly in developing countries undergoing their epidemiological transition phase comparable significant rises have been observed. ${ }^{4}$ Accordingly, the World Health Organization (WHO) includes both obesity and asthma among the major chronic disorders representing world-wide public health priorities. ${ }^{5}$

Given this dramatic rise in the prevalence of obesity and asthma, it is not surprising that there has been an increasing body of literature on the association between Body Mass Index (BMI) and asthma. $^{6}$

Obesity may have effects on both the upper and lower airway, ${ }^{7}$ and this hypothesis is supported to a certain extent by the observation that BMI, the best single measure of body adiposity, ${ }^{8}$ seems to be a reliable predictor of allergic respiratory symptoms and airways hyperresponsiveness (AHR). ${ }^{9}$ In fact, recent literature emphasises the role of obesity in inducing a pro-inflammatory state due to increased levels of different pro-inflammatory cytokines. This might be implicated in the genesis of chronic inflammation of the airway system $^{10}$ similar to those observed in asthma which is characterized by persistent infiltration of eosinophils, T-lymphocytes and mast cells combined with different cytokines. In this respect exhaled Nitric Oxide (eNO) has been shown to tightly reflect this airway inflammation ${ }^{11}$ and its fractional concentration in exhaled air (FeNO) has been recently accepted by the PRACTALL Consensus Report for the Diagnosis, Management and Treatment of Childhood Asthma as a logical complementary item in the follow-up of bronchial inflammation. ${ }^{12}$ 
The reported association between increased BMI and onset of AHR has been elegantly demonstrated by Litonjua et al. ${ }^{13}$ in a longitudinal study of aging and has been further confirmed by two large cross-sectional studies performed in adults. ${ }^{14,15}$ This is in contrast with other epidemiological studies performed in childhood where this association has not been universally observed. ${ }^{16,17,18}$ This represents an important discordance of the recent literature as it might indicate that different factors such as duration of obesity and subsequent physiological changes of airway structures might play an important role in the development of obesity induced AHR.

Pre-pubertal children are a special study population as the shorter duration combined with better control of both diseases eliminates confounding factors commonly present in older subjects. In fact, this kind of population offers the exclusive opportunity to tangle whether obesity and asthma explicate an independent effect on lung function testing or influence themselves in a reciprocal manner.

Therefore, with the primary aim to establish the possible dependent or independent role of asthma and obesity on airway system function we evaluated AHR and bronchial inflammation expressed by FeNO in a group of obese and non obese asthmatic children in comparison to non-asthmatic obese and normal-weight pre-pubertal children. 


\section{MATERIALS AND METHODS}

\section{Study subjects}

Clinical, anthropometric measurements and respiratory parameters of a group of 118 Caucasian prepubertal children referred to the Children Obesity Clinic, to the Paediatric Allergy and Respiratory Clinic and to the Department of Paediatrics, University of Chieti, Italy, were sequentially evaluated between May 2008 and August 2008.

Asthma was classified according to Global Initiative for Asthma (GINA) guidelines ${ }^{19}$ as intermittent asthma, mild persistent, moderate persistent and severe persistent asthma. The diagnosis was established by a single paediatric respiratory physician on the basis of a clinical history of repeated episodes of coughing, dyspnoea and wheezing, according to American Thoracic Society - European Respiratory Society (ATS-ERS) criteria. $^{20}$ Only subjects who fulfilled the definition of intermittent/mild persistent asthma were recruited. Low dose inhaled corticosteroids (ICSs) therapy was withdrawn for not more than weeks before the study evaluation. Over this period all children were closely monitored by the medical staff of the Paediatric Allergy and Respiratory Clinic, none experienced any adverse event and at the time of the study evaluation all subjects were symptom-free.

Obesity was defined as Body Mass Index [BMI] above 2 Standard Deviations (SD) for the mean of age and sex. ${ }^{21}$ In all subjects endocrine diseases as cause for obesity were excluded prior to study entry. None of the non-asthmatic obese children had a personal history for asthma and allergic diseases.

We recruited as controls a group of healthy children, comparable for age, gender, and pubertal stage, who were admitted to the Department of Paediatrics for minor diseases. None of the children had a personal history for asthma and allergic diseases, and all were otherwise in a good health. Anthropometric measurement and respiratory function were assessed only after complete recovery of the disease. 
Exclusion criteria for all children were: presence of upper or lower respiratory infections including asthma during the previous 4 weeks, congenital abnormalities of cardio-respiratory system, chest or skeletal deformities, or neuromuscular system disease, chronic and autoimmune disease, gastrooesophageal reflux, presence of medical condition in which exercise was forbidden. None of the children was taking any medication.

Based on the presence or absence of asthma and according to BMI, the study population was divided into four groups:

1. Obese Asthmatic Children [ObA] (sixteen boys and 14 girls);

2. Normal-weight Asthmatic Children [NwA] (sixteen boys and 14 girls);

3. Non-Asthmatic Obese Children [Ob] (fourteen boys and 16 girls);

4. Non-Asthmatic Normal-weight Children [Nw] (fourteen boys and 14 girls).

All children underwent a complete physical examination including anthropometric parameters [height, weight]. Pubertal stage was defined on the basis of breast development in girls and genital development in boys according to the criteria of Tanner (all subjects had pre-adolescent characteristics corresponding to stage 1). Respiratory function was assessed by standard Flow/Volume curves at baseline and after Six-Minute Walk Test (6MWT), and respiratory inflammatory status was assessed by FeNO. Only asthmatic children performed allergy evaluation by Skin Prick Test (SPT), and blood sample was taken for specific IgE measurement.

Written informed consent was obtained from all parents and oral consent from all children.

The study was approved by Ethical Committee of University of Chieti.

\section{Methods}

\section{Anthropometric measurements}

Body weight was determined to the nearest $0.1 \mathrm{Kg}$, and height was measured in triplicate with Harpenden stadiometer to the nearest $0.1 \mathrm{~cm}$. As fatness indices, we used BMI (the weight in kilograms divided by the square of the height in meters). SDS-height and BMI-SDS were calculated 
as difference between the individual observed value and the reference mean for age and sex, divided by the corresponding standard deviation. ${ }^{22}$

\section{Spirometric and Flowmetric Measurements:}

\section{Baseline Flow/Volume curves}

Lung function evaluation was performed by Flow/Volume curves (KitMicro Spirometer 7.3a COSMED) in the standing position with nose-clip until two consecutive technically acceptable curves were achieved, according to ATS/ERS Guidelines. ${ }^{23}$ The main spirometric parameters included: Forced Expiratory Volume in $1 \mathrm{sec}\left(\mathrm{FEV}_{1}\right)$, Forced Vital Capacity (FVC), FEV $/ \mathrm{FVC}_{\text {, }}$ and Forced Expiratory Flows between $25 \%$ and $75 \%$ of the FVC $\left(\mathrm{FEF}_{25-75}\right)$ and the results are expressed as Z-scores according to Stanojevic S et al. ${ }^{24}$ Peak Expiratory Flow (PEF) and Maximal Expiratory Flows at $75 \%$ of the FVC $\left(\mathrm{MEF}_{75}\right)$ were expressed as a percentage of theoretical values for age, gender, and height according to Quanjer PH et al. ${ }^{25}$

\section{Six-Minute Walk Test (6MWT)}

In order to estimate the bronchial hyperresponsiveness, after baseline lung function testing, a 6MWT was performed according to standard protocol. ${ }^{26}$ The target of the test was to achieve 6 minutes of free walk until the hearth-rate was $80-90 \%$ of the predicted maximum (calculated as 220 - age in years), according to ATS/ERS recommendations for exercise challenge test in older children. ${ }^{27}$ Spirometry was performed in duplicate sets at $1,3,5,10$ and 20 minutes post-exercise. The better of the two curves was selected as the representative value at each interval, but differences between the two values of $\mathrm{FEV}_{1}$ had to be $<5 \%$. Exercise response was defined as the greatest decrease in $\mathrm{FEV}_{1}$ expressed as a percentage of the baseline values. A bronchial obstruction response to exercise was considered positive when the $\mathrm{FEV}_{1}$ reduction from baseline was greater than $12 \% .^{28}$

\section{Allergic sensitization}

Skin Prick Test (SPT) were performed and serum specific IgE were measured for the most common respiratory allergens: Dust Mite (Dermatophagoides Pteronyssinus and Farinae), Grass, Parietaria, 
Artemisia Vulgaris, Olive, Cypress, Lime, Stone, Elm, Plane, Cat and Dog dander, Alternaria Alternata and Aspergillus Fumigatus (moulds). Determination of Allergen-Specific IgE was made by an Immunoenzymatic Allergo-sorbent Test (Cap test Pharmacia). ${ }^{29,30}$

Respiratory inflammation marker

FeNO was determined with an on-line method using a single breath exhalation and a sensitive chemiluminescence assay (Ecomedics CLD 88), according to ATS-ERS. ${ }^{31}$ Patients made an inspiration of eNO-free air via a mouthpiece immediately followed by full exhalation at a constant rate $(50 \mathrm{ml} / \mathrm{sec})$ for at least 5 seconds. The mean of three readings at the end of the expiration (plateau phase) was taken as the representative value for each measurements. $12 \mathrm{ppb}$ or more were considered positive, according to ATS-ERS criteria. ${ }^{32}$

\section{Statistical analysis}

All values were expressed as Median and Interquartile Range.

Kruskal Wallis Test was performed for evaluating differences between the four groups (ObA, NwA, $\mathrm{Ob}, \mathrm{Nw})$. Statistical significance level was $\mathrm{p}<0.05$. Subsequently, differences within the single groups were tested by Mann-Whitney Test, adjusting the significance level by $\mathrm{p}<0.008$. Differences in functional respiratory baseline parameters and after 6MWT within each group were analyzed using Wilcoxon Signed Ranks Test. Categorical variables were tested by Pearson's chi-square $\left(\mathrm{X}^{2}\right)$ test.

A multiple analysis of covariance (MANCOVA) was performed to investigate the independent effect of obesity and asthma on respiratory indices $\left(\mathrm{PEF}, \mathrm{MEF}_{75}\right.$ and $\left.\mathrm{FEV}_{1} / \mathrm{FVC}\right)$ and bronchial inflammation (FeNO), after adjusting for gender, age and height.

Statistical significance level was $\mathrm{p}<0.05$.

All calculations were made with the computer program SPSS (Statistical Package for the Social Science), version 16.0 software for Windows. 


\section{RESULTS}

Anthropometric measurements and respiratory functional data of the whole study population are reported in Table 1. The four groups were similar for age, gender, and SDS-height.

As expected BMI-SDS was similar between ObA and Ob children, but was significantly different between obese children and normal-weight children (ObA vs NwA $\mathrm{p}=0.0004$; ObA vs Nw: $\mathrm{p}=0.0008 ;$ Ob vs NwA $\mathrm{p}=0.0001 ;$ Ob vs Nw: $\mathrm{p}=0.0002)$.

All the asthmatic children were sensitized to Dermatophagoides Pteronyssinus.

\section{Baseline Respiratory Functional Parameters}

No significant differences were found for $\mathrm{FVC}, \mathrm{FEV}_{1}$, and $\mathrm{FEF}_{25-75} \mathrm{Z}$-scores between the four groups, whereas $\mathrm{FEV}_{1} / \mathrm{FVC} \mathrm{Z}$-score resulted significantly different (Tab 1). In fact, this parameter was significantly lower in the ObA group compared to the $\mathrm{Nw}$ group $(\mathrm{p}=0.005)$. Moreover a significant difference was detected between the four groups in terms of PEF $(\mathrm{p}=0.03)$ and $\mathrm{MEF}_{75}$ ( $\mathrm{p}=0.001)$ (Fig 1). By comparing the four groups directly no further significances could be detected for $\mathrm{PEF}$, whereas $\mathrm{MEF}_{75}$ was significantly lower in the ObA group and the Ob group compared to the Nw group $(\mathrm{p}=0.004$ and $\mathrm{p}=0.0001$, respectively)

\section{Respiratory Functional Parameters after 6MWT}

After 6MWT no significant differences were found in post-FVC and post-FEF $25-75$ Z-scores among the four groups (Tab 1). Although post-FEV $1 / \mathrm{FVC} \mathrm{Z}^{\mathrm{Z}}$-scores resulted significant different between the four groups, no further differences were detected by comparing the four groups directly. In contrast, post-FEV 1 Z-score resulted significantly lower in NwA children when compared to $\mathrm{Ob}$ children and $\mathrm{Nw}$ children $\left(\mathrm{p}=0.006\right.$ and $\mathrm{p}=0.006$, respectively). Post-PEF and post-MEF $\mathrm{M}_{75}$ resulted significantly different between the four groups ( $\mathrm{p}=0.01$, both). In fact, post-PEF was significantly lower in ObA children when compared to $\mathrm{Nw}$ children $(\mathrm{p}=0.002)$. This was associated with significantly lower values of post- $\mathrm{MEF}_{75}$ in the $\mathrm{ObA}$ group and the Ob group when compared to the Nw group ( $\mathrm{p}=0.003$ and $\mathrm{p}=0.007$, respectively). 
Changes in respiratory parameters after 6MWT within each group are shown in Table 2. Post$\mathrm{FEV}_{1} / \mathrm{FVC} \mathrm{Z}$-score was significantly lower in the ObA group, while in NwA children a significant reduction was detected for post-FEV $\mathrm{F}_{1}$, post-FVC and post-FEF $\mathrm{F}_{25-75} \mathrm{Z}$-scores. In contrast no changes were detected for the $\mathrm{Ob}$ and $\mathrm{Nw}$ groups.

A positive response to exercise challenge was found in $5 \mathrm{ObA}$ children and $7 \mathrm{NwA}$ children compared to only $2 \mathrm{Ob}$ children. As expected none of the healthy control children experienced a fall in $\mathrm{FEV}_{1}$ greater than $12 \%$.

Respiratory inflammation marker

FeNO values were significantly different across all four groups ( $\mathrm{p}=0.0002)$ (Tab. 1).

In fact FeNO values were significantly higher in the ObA group and the NwA group compared to the Ob group ( $\mathrm{p}=0.008$ and $\mathrm{p}=0.0002$, respectively) and to the $\mathrm{Nw}$ group $(\mathrm{p}=0.0001$ and $\mathrm{p}=0.0003$, respectively).

Furthermore FeNO was significantly higher in the $\mathrm{Ob}$ group when compared to the Nw group $(\mathrm{p}=0.0004)$. In contrast no differences were detected between the two asthmatic groups.

Effect of asthma and obesity on respiratory functional parameters and bronchial inflammation In order to investigate the role of asthma and obesity on resulted significant different baseline respiratory variables and FeNO, a multiple analysis of covariance was performed. Asthma was significantly and independently related to FeNO values, whereas no association was found for obesity. In contrast obesity was significantly and independently related to PEF and $\mathrm{MEF}_{75}$. In the same model no relationship was found for asthma and obesity on $\mathrm{FEV}_{1} / \mathrm{FVC}$ Z-score (Table 3). 


\section{DISCUSSION}

Although the effect of obesity on pulmonary function tests has been extensively investigated in adults, the number of similar studies in children is limited and confirm the controversial results observed in adults between obesity and AHR. In this study we compare for the first time obese asthmatic with obese non-asthmatic pre-pubertal children and healthy controls with the aim to analyse the reciprocal influences of obesity and asthma on lung function and bronchial inflammation. Our findings clearly demonstrate that while an asthmatic status is tightly and directly involved in AHR and bronchial inflammation, obesity mainly affects the upper airways flows.

As obese children often experience dyspnoea and breathlessness during physical activities it is a crucial clinical question as to whether these symptoms are effectively related to AHR such as in asthmatic children. In order to explore this possibility a 6MWT was performed. While basal values of spirometric indices were normal in all examined groups, in ObA and NwA children exercise challenge induced AHR documented by the reduction of functional respiratory parameters. In contrast in $\mathrm{Ob}$ and $\mathrm{Nw}$ children no changes of any of the obtained variables were detected. This is confirmed by the number of children exhibiting a positive response to exercise defined as fall in FEV1 greater than $12 \%$. In fact within the asthmatic children 12 subjects met this definition compared to only 2 obese children. In agreement with our data, epidemiological studies do not uniformly support the conclusions that obesity leads to airflow limitation, AHR or asthma. In this respect Schachter and co-workers showed in a group of 1971 adults, that although BMI was associated with a clinical diagnosis of asthma and subjective symptoms of dyspnoea and wheeze, airflow obstruction or AHR subsequent to histamine challenge could not be detected in the sole obese subjects. ${ }^{16}$ Similar findings were obtained by Bibi et al. ${ }^{17}$ who demonstrated in a large population of pre-pubertal children that bronchodilation could not be induced by salbutamol inhalation in non-asthmatic obese subjects. ${ }^{33}$ These data demonstrate that obesity should not be considered as being a risk factor for AHR in pre-pubertal children. Furthermore asthma like symptoms especially during physical activity should not be overestimated by parents and medical 
staff. This is of paramount relevance as it might induce inappropriate treatment and refrain children from performing sports leading to a vicious circle impeding improvement of both obesity and respiratory symptoms.

Interestingly in the $\mathrm{ObA}$ and $\mathrm{Ob}$ groups we documented lower basal values of $\mathrm{MEF}_{75}$ when compared to healthy controls. Furthermore PEF values were significantly different across the four groups with a tendency of lower values in the two obese groups. In fact, by performing a multiple analysis of covariance obesity was significantly and independently related to $\mathrm{MEF}_{75}$ and to PEF, while this association was not found for asthma. Similar data were documented by two previous studies $^{34,35}$ where obesity was associated with a significant reduction in $\mathrm{FEF}_{25-75}$. These data suggests that obesity might play a primary role on upper airway flows, and despite being possibly explained by fatty infiltration of muscles narrowing directly the upper airway, recent literature suggest that this functional parameter might be used as an early predictor of sub-clinical asthma. ${ }^{36}$ In order to obtain a complete evaluation of the bronchial status we performed also FeNO analysis. In effect, recent studies revealed that FeNO is a potentially useful measure to evaluate the role of airways inflammation in asthma, as it represents the forerunner of the most important event namely remodelling of bronchial airways, ${ }^{37}$ offering therefore a logical complementary item to the only use of clinical and functional data. In our study, as expected, both groups of asthmatic children presented highly elevated FeNO values when compared to $\mathrm{Ob}$ children and normal controls reflecting the underlying bronchial inflammation process. However, data from animal and human studies clearly demonstrate that the enhancement of normal adipose tissue in obesity leads to a systemic pro-inflammatory state. ${ }^{38}$ Adipose tissue from obese individuals expresses a number of pro-inflammatory molecules, such as leptin, tumor necrosis factor- $\alpha$, IL-6, transforming growth factor- $\beta 1$, and C-reactive protein, and there appears to be significant overlap between the immune function of adipocytes and the function of T-lymphocytes and macrophagues, particularly with respect to the elaboration of inflammatory cytokines. ${ }^{39,40}$ Although a conclusive relationship between obesity and airway inflammation has not yet to been described, it could be argued that the 
role of the pro-inflammatory state underlying the main metabolic and cardiovascular complications in obesity might play a pivotal role in determining airways inflammation independently of any allergic mechanisms. This might explain the findings of our study where FeNO values were significantly higher in $\mathrm{Ob}$ children when compared to healthy controls, and the findings of Santamaria et al. ${ }^{41}$ who found a positive correlation between FeNO and BMI in healthy children. However it needs to be acknowledged that in the multiple analysis of covariance obesity was not a predictor for increased FeNO values as only asthmatic status remained as such. This apparent contrasting findings might be partially explained by the age group of our study population as obesity related inflammation might not have reached its full implication and a possible involvement of the respiratory system might require a long standing history of obesity.

In this respect an important limitation of this study is the cross sectional design which does not allow to speculate on the full clinical implications of our findings. In fact, as puberty is a well known risk factor for developing obesity related complications it might be of crucial interest to obtain longitudinal data starting in pre-puberty and lasting through all pubertal stages. This would allow to fully explore this intriguing relationship and to not underestimate the possible role of obesity on the development of bronchial inflammation.

In conclusion, while AHR and airways inflammation are clearly associated to an asthmatic status, obesity seems to induce reduction of upper airway flows combined with a certain degree of early pro-inflammatory airways changes. Longitudinal data are required in order to clarify whether these changes might represent risk factor for asthma later on in life.

\section{Acknowledgements}

We thank all nurses of the Department of Pediatrics, University of Chieti, in particular Di Santo D, Di Luca D, Diomedi A, for their daily support in clinical research and care of children. 


\section{REFERENCES}

1. Ogden CL, Carroll MD, Curtin LR, McDowell MA, Tabak CJ, Flegal KM. Prevalence of overweight and obesity in the United States, 1999-2004. JAMA 2006;295(13):1549-1555.

2. Binkin N, Fontana G, Lamberti A, Cattaneo C, Baglio G, Perra A, Spinelli A. A national survey of the prevalence of childhood overweight and obesity in Italy. Obes Rev 2009 Sep 17.

3. Moorman JE, Rudd RA, Johnson CA, King M, Minor P, Bailey C, Scalia MR, Akinbami LJ; Centers for Disease Control and Prevention (CDC). MMWR Surveill Summ 2007;56(8):1-54.

4. World Health Organization. Obesity: preventing and managing the global epidemic. WHO Technical Report Series 894. Geneva, Switzerland, WHO, 2000.

5. World Health Organization. Preventing chronic diseases: a vital investment. Geneva, Switzerland: WHO, 2005.

6. Figueroa-Munoz JI, Chinn S, Rona RJ. Association between obesity and asthma in 4-11 year old children in the UK. Thorax 2001;56:133-137.

7. Deane S, Thomson A. Obesity and the pulmonologist. Arch Dis Child 2006;91(2):188-191.

8. Power C, Lake JK, Cole TJ. Measurement and long term health risks of child and adolescent fatness. Int J Obes Relat Metab Disord 1997;21:507-526.

9. Gennuso J, Epstein LH, Paluch RA, Cerny F. The relationship between asthma and obesity in urban minority children and adolescent. Arch Pediatr Adolesc Med 1998;152(12):11971200.

10. Visser M, Bouter LM, McQuillan GM, Wener MH, Harris TB. Elevated C-reactive protein levels in overweight and obese adults. JAMA 1999;282:2131-5.

11. Payne DN, Adcock IM, Wilson NM, Oates T, Scallan M, Bush A. Relationship between exhaled nitric oxide and mucosal eosinophilic inflammation in children with difficult 
asthma, after treatment with oral prednisolone. Am J Respir Crit Care Med 2001;164:13761381.

12. Bacharier LB, Boner A, Carlsen K-H, Eigenmann PA, Frischer T, Götz M, Helms PJ, Hunt J, Liu A, Papadopoulos N, Platts-Mills T, Pohunek P, Simons FE, Valovirta E, Wahn U, Wildhaber J; European Pediatric Asthma Group. Diagnosis and treatment of asthma in childhood: a PRACTALL Consensus Report. Allergy 2008;63:5-34.

13. Litonjua AA, Sparrow D, Celedon JC, DeMolles D, Weiss ST. Association of body mass index with the development of methacholine airway hyperresponsiveness in men: the Normative Aging Study. Thorax 2002;57:581-585.

14. Chinn S, Jarvis D, Burney P. Relation of bronchial responsiveness to body mass index in the ECRHS. European Community Respiratory Health Survey. Thorax 2002;57:1028-1033.

15. Celedon JC, Palmer LJ, Litonjua AA, Weiss ST, Wang B, Fang Z, Xu X. Body mass index and asthma in adults in families of subjects with asthma in Anqing, China. Am J Respir Crit Care Med 2001;164:1835-1840.

16. Schachter LM, Salome CM, Peat JK, Woolcock AJ. Obesity is a risk for asthma and wheeze but not airway hyperresponsiveness. Thorax 2001;56:4-8.

17. Bibi H, Shoseyov D, Feigenbaum D, Genis M, Friger M, Peled R, Sharff S. The relationship between asthma and obesity in children: is it real or a case of over diagnosis? J Asthma 2004;41(4):403-410.

18. Wickens K, Barry D, Friezema A, Rhodius R, Bone N, Purdie G, Crane J. Obesity and asthma in 11-12 year old New Zealand children in 1989 and 2000. Thorax 2005;60:7-12.

19. Global Strategy for Asthma Management And Prevention, Global Initiative for Asthma (GINA) World Report 2006. Available from: http//www.ginasthma.org.

20. National Asthma Education and Prevention Program. NAEPP expert panel report guidelines for the diagnosis and management of asthma - update on selected topics 2002. National Institutes for Health 2006. 
21. Kiess W, Reich A, Müller G, Galler A, Kapellen T, Raile K, Böttner A, Seidel B, Kratzsch J. Obesity in childhood and adolescence: clinical diagnosis and management. J Pediatr Endocrinol Metab 2001;14(6):1431-1440.

22. Lindgren G, Strandell A, Cole T, Healy M, Tanner J. Swedish population standards for height, weight and body mass index attained at 6 to 16 years (girls) or 19 years (boy). Acta Pediatr 1995;84:1019-1028.

23. Laszlo G. Standardisation of lung function testing: helpful guidance from the ATS/ERS Task Force. Thorax 2006;61(9):744-746.

24. Stanojevic S, Wade A, Stocks J, Hankinson J, Coates AL, Pan H, Rosenthal M, Corey M, Lebecque P, Cole TJ. Reference Ranger for Spirometry Across All Ages: A New Approach. Am J Respir Crit Care Med 2008;177:253-260.

25. Quanjer PH, Borsboom GJ, Brunekreef B, Zach M, Forche G, Cotes JE, Sanchis J, Paoletti P. Spirometric reference values for white European children and adolescents: Polgar revisited. Pediatr Pulmonol 1995;19(2):135-142.

26. ATS Committee on Proficiency Standards for Clinical Pulmonary Function Laboratories. ATS statement: guidelines for the six-minute walk test. Am J Respir Crit Care Med 2002;166:111-117.

27. Crapo RO, Casaburi R, Coates AL, Enright PL, Hankinson JL, Irvin CG, MacIntyre NR, McKay RT, Wanger JS, Anderson SD, Cockcroft DW, Fish JE, Sterk PJ. Guidelines for Methacholine and Exercise Challenge Testing-1999. This official statements of the American Thoracic Society was adopted by the ATS Board of Directors, July 1999. Am J Respir Crit Care Med 2000;161:309-329.

28. Godfrey S, Springer C, Bar-Yishay E, Avital A. Cut-off points defining normal and asthmatic bronchial reactivity to exercise and inhalation challenges in children and young adults. Eur Respir J 1999;14:659-666. 
29. Terho E, Frew AJ. Type III allergy skin testing. Position statement for EAACI Subcommittee on Skin Tests and Allergen Standardization. Allergy 1995;50(5):392-396.

30. Wolkerstorfer A, Wahn U, Kjellman NI, Diepgen TL, De Longueville M, Oranje AP. Natural course of sensitization to cow's milk and hen's egg in childhood atopic dermatitis: ETAC Study Group. Clin Exp Allergy 2002;32(1):70-73.

31. American Thoracic Society; European Respiratory Society. ATS/ERS recommendations for standardized procedures for the online and offline measurement of exhaled lower respiratory nitric oxide and nasal nitric oxide, 2005. Am J Respir Crit Care Med 2005;171(8):912-930.

32. Baraldi E, de Jongste JC; European Respiratory Society; American Thoracic Society. Measurement of exhaled nitric oxide in children, 2001. Eur Respir J 2002;20(1):223-237.

33. Bibi H, Montgomery M, Paster kamp H, Chernick V. Relationship between response to inhaled salbutamol and methacholine bronchial provocation in children with suspected asthma. Pediatr Pulmonol 1991;10:244-248.

34. Spathopoulos D, Paraskakis E, Trypsianis G, Tsalkidis A, Arvanitidou V, Emporiadou M, Bouros D, Chatzimichael A. The Effect of Obesity on Pulmonary Lung Function of School Aged Children in Greece. Pediatr Pulmonol 2009;44:273-280.

35. Ülger Z, Demir E, Tanaç R, Gökşen D, Gülen F, Darcan Ş, Can D, Coker M. The effect of childhood obesity on respiratory function tests and airway hyperresponsiveness. The Turkish Journal of Pediatrics 2006;48:43-50.

36. Drewek R, Garber E, Stanclik S, Simpson P, Nugent M, Gershan W. The $\mathrm{FEF}_{25-75}$ and its decline as a predictor of methacholine responsiveness in children. J Asthma 2009;46(4):375381.

37. van Veen IH, Sterk PJ, Schot R, Gauw SA, Rabe KF, Bel EH. Alveolar nitric oxide versus measures of peripheral airway dysfunction in severe asthma. Eur Respir J 2006;27(5):951956. 
38. Fantuzzi G. Adipose tissue, adipokines, and inflammation. J Allergy Clin Immunol 2005;115:911-919.

39. Weisberg SP, McCann D, Desai M, Rosenbaum M, Leibel RL, Ferrante AW Jr. Obesity is associated with macrophage accumulation in adipose tissue. J Clin Invest 2003;112:17961808.

40. Wellen KE, Hotamisligil GS. Obesity-induced inflammatory changes in adipose tissue. J Clin Invest 2003;112:1785-1788.

41. Santamaria F, Montella S, De Stefano S, Sperlì F, Barbarano F, Valerio G. Relationship between exhaled nitric oxide and body mass index in children and adolescent. J Allergy Clin Immunol 2005;116:1163-1164. 


\title{
The reciprocal influences of asthma and obesity on lung function in prepubertal children.
}

\author{
Consilvio Nicola Pietro, MD; Di Pillo Sabrina, MD; Verini Marcello, MD; Tommaso de Giorgis, \\ MD; Anna Cingolani, MD; Fabio Masuccio, MD; Francesco Chiarelli, PhD; Angelika Mohn, MD.
}

Department of Pediatrics, University of Chieti, Chieti, Italy.

Short title: Asthma and obesity impact on lung function.

\author{
Word count: 2919 \\ Funding: none \\ Conflict of Interest: none
}

Keywords: Body Mass Index-Standard Deviation Score, obesity, asthma, Fractional exhaled Nitric Oxide, Lung Function Testing, Airways Hyperresponsiveness.

\section{Correspondence:}

Angelika Mohn
Department of Pediatrics
University of Chieti
Via Dei Vestini 5
66100 Chieti
Tel +390871 358827
Fax+390871 584731
Email amohn@ @nich.it




\begin{abstract}
As the incidence of obesity and asthma increase consistently, the reciprocal influences of both on lung function, airways hyperresponsiveness (AHR) and bronchial inflammation were analysied in a group of 118 caucasian prepubertal children.

Anthropometric measurements and respiratory parameters (Flow/Volume curves, "free run" Exercise Challenge Test, FeNO) were evaluated and the study population was divided into four groups according to Body Mass Index and the presence or absence of asthma: Obese Asthmatic, Normal-weight Asthmatic, Obese non-Asthmatic, Normal-weight non-Asthmatic children.

MEF75\% was significantly lower in obese asthmatic and non-asthmatic children compared to healthy controls and the influence of obesity on MEF75\% was confirmed by multiple linear regression. After the "free-run" Exercise Challenge Test all analysed respiratory parameters decreased significantly in asthmatic obese and non-obese children, in contrast in non-asthmatic obese children no differences were found. FeNO analysis demonstrate significantly higher values in asthmatic children compared to obese non-asthmatic and healthy controls. Furthermore FeNO was significantly higher in obese non-asthmatic children when compared to healthy controls.

In conclusion, while AHR and airways inflammation are clearly associated to an asthmatic status, obesity seems to induce early proinflammatory airways changes combined with reduction of higher intrathoric airway flows.
\end{abstract}




\section{INTRODUCTION}

Over the past 20 years the incidence and prevalence of obesity have steadily increased. The most recent data from the Centers for Disease Control's (CDC) Third National Health and Nutrition Examination Survey (NHANES III) revealed a prevalence of obesity - defined as a body mass index (BMI) in excess of $95 \%$ of the age specific distribution - of $14 \%$ in children aged $6-11$ surveyed between 1988 and 1994. ${ }^{1}$ In comparison NHANES II, conducted between 1976 and 1980, found a prevalence of obesity of $7.6 \%$ for the same population. This has been accompanied by a similar rise in the association rates of asthma. The CDC self-reported prevalence of asthma in children aged 5 - 14 rose from 42.8 per 1000 in 1980 to 74.4 per 1000 in $1994 .^{2}$ Epidemiologists have reported that both obesity and asthma are "endemic" in developed countries 3,4 and "epidemic" in developing countries undergoing their epidemiological transition phase. ${ }^{5}$ Accordingly, the World Health Organization (WHO) includes both obesity and asthma among the major chronic disorders representing world-wide public health priorities. ${ }^{6}$

Given the dramatic rise in the prevalence of obesity and asthma, it is not surprising that there has been an increasing body of literature on the association between BMI and asthma. ${ }^{7}$

Obesity may have effects on both the upper and lower airway $;^{8}$ and this hypothesis is supported to a certain extent by the observation that BMI, the best single measure of body adiposity, ${ }^{9}$ seems to be a reliable predictor of allergic respiratory symptoms and airways hyperresponsiveness (AHR). ${ }^{10,11,12}$ Infiltration by eosinophils, mast cells and T lymphocytes is a key feature of airway inflammation in asthma $^{13}$ and an increased eosinophil number in induced sputum of asthmatic children is tightly linked to current asthma symptoms and AHR. ${ }^{14}$ Recently, exhaled Nitric Oxide (eNO) has been shown to have a good correlation with airway eosinophilic inflammation ${ }^{15}$ and its fractional concentration in exhaled air (FeNO) has been accepted to be a useful indicator of airway inflammation. On the other hand recent literature emphasises the role of obesity in inducing a proinflammatory state as obesity is associated with increased levels of leptin and proinflammatory 
cytokines such as interleukin (IL)-6 and IL-1 which might be implicated in a possible up-regulate inflammation of the airway system. ${ }^{16}$

The reported association between increased BMI and onset of AHR has been elegantly demonstrated by Litonjua et al. ${ }^{17}$ in a longitudinal study of aging; and has been further confirmed by two large cross-sectional studies. ${ }^{18,19}$ This is in contrast with epidemiologic studies where this association has not been universally observed, indicating that different factors such as duration of obesity, physiological changes of airway structures might play an important role on the development of this relationship.

Prepubertal children might represent a special study population in order to investigate the reciprocal and independent influences of obesity and asthma on lung function testing, and bronchial indices of flogosis as both diseases should not necessarily having caused physiological changes commonly observed in older subjects.

We therefore evaluated AHR and bronchial inflammation expressed by FeNO in obese and non obese asthmatic children in comparison with non asthmatic obese and normalweight prepubertal children. 


\section{METHODS}

\section{Study subjects}

Clinical, anthropometric measurements and respiratory parameters of a group of 118 Caucasian prepubertal children referred to the Department of Pediatrics, Children Obesity Clinic and to the Allergological and Pneumological Unity of the Pediatric Department, University of Chieti, Italy, between May 2008 and August 2008, were evaluated.

According to Body Mass Index [BMI], and based on the presence or absence of asthma, the study population was divided into four groups:

1. Obese Asthmatic Prepubertal Children [ObA] (16 M and 14 F);

2. Normal-weight Asthmatic Prepubertal Children [NwA] (16 M and 14 F);

3. Non-Asthmatic Obese Prepubertal Children [Ob] (14 M and 16 F);

4. Non-Asthmatic Normal-weight Prepubertal Children [Nw] (14 M and 14 F)

- Pubertal stage was defined on the basis of breast development in girls and genital development in boys according to the criteria of Tanner (all subjects had pre-adolescent characteristics corresponding to stage 1$)$.

- A complete physical examination including [height, height Standard Deviation Score (SDS), weight, weight-SDS, BMI, BMI-SDS]. Children with values between -2 and 2 SD were defined normal-weight, while children with BMI above 2 SD were defined obese..$^{20,21}$

- Asthma was classified according to GINA guidelines ${ }^{22}$ as intermittent asthma, mild persistent, moderate persistent and severe persistent asthma. All subjects had been admitted for intermittent/mild persistent asthma and the diagnosis was made by a pediatric respiratory physician on the basis of clinical history of repeated episodes of coughing, dyspnea and wheezing, according to ATS-ERS criteria. ${ }^{23}$ To evaluate the bronchial reactivity was made an Exercise Challenge Test. Moreover, to evaluate the bronchial inflammation all children underwent FeNO analysis. To evaluate the allergic sensitization we made Skin Prick Test (SPT) and serum specific $\operatorname{IgE}$ measurements for the most common respiratory allergens. 
Asthmatic children had received an inhaled corticosteroids (ICS) therapy, but were free from therapy for at least 2 weeks before the study evaluation; and all obese children were therapy-free.

All the subjects were symptom-free and had no clinical evidence of cardiopulmonary disease in a preceding evaluation. Exclusion criteria from the study for all groups were: presence of upper or lower respiratory infection or exacerbation of asthma during the previous 4 weeks, not well controlled asthma according to current Global Initiative for Asthma (GINA) classification of asthma, ${ }^{24}$ congenital abnormalities of cardiorespiratory system, chest or skeletal deformities, or neuromuscular system disease, chronic and autoimmune disease, gastroesophageal reflux, presence of medical condition in which exercise was forbidden.

Written informed consent was obtained from all parents and oral consent from all children.

The study was approved by Ethical Committee of University of Chieti.

\section{Methods}

Anthropometric measurements

Body weight was determined to the nearest $0.1 \mathrm{Kg}$, and height was measured in triplicate with Harpenden stadiometer to the nearest $0.1 \mathrm{~cm}$.

We used BMI for fatness indexes (the weight in kilograms divided by the square of the height in meters); and also BMI expressed as a continuous variable in standard deviation score (BMI-SDS) units (z-score), determined as difference between the individual observed value and the reference mean for age and sex, divided by the corresponding standard deviation. ${ }^{25}$

\section{Functional respiratory data}

Evaluations were made by Flow/Volume curves (KitMicro Spirometer 7.3a-COSMED), according ATS/ERS Guidelines, ${ }^{26}$ and the main spirometric tests were considered: Forced Expiratory Volume in $1 \mathrm{sec}$ (FEV1), Forced Vital Capacity (FVC), Peack Expiratory Flow (PEF) and Maximal 
Expiratory Flows at 75\%, 50\% and 25\% of the Forced Vital Capacity (MEF75\%, MEF50\%, MEF25\%). All the tests were expressed as a percentage of theoretical values for eight.

To evaluate the bronchial hyperresponsiveness measurements are performed in the standing position, with nose-clip until two consecutive technically acceptable curves are achieved. After the free-run, spirometry was measured in duplicate sets at 1, 3, 5, 10 and 20 minutes post-exercise. The better of the two curves was selected as the representative value at each interval, but differences between the two values of FEV1 had to be $<5 \%$. The target was to achieve 6 minutes of "free run" to increase hart-rate to $80 \%$ in the maximum for at least 4 minutes according to ATS/ERS recommendations for exercise challenge test in older children. ${ }^{27,28}$ Exercise response was defined as the greatest decrease in FEV1 expressed as a percentage of the baseline values. A bronchoconstriction response to exercise was considered as positive when the FEV1 decrease from baseline was greater than $13 \% .^{29}$

\section{Allergic sensitization}

Was evaluated by Skin Prick Test (SPT) and serum specific IgE measurements for the most common respiratory allergens: Dust Mite (Dermatophagoides Pteronyssinus and Farinae), Grass, Parietaria, Artemisia Vulgaris, Olive, Cypress, Lime, Stone, Elm, Plane, Cat and Dog dander, Alternaria Alternata and Aspergillus Fumigatus (moulds). Determination of Allergen-Specific IgE was made by an Immunoenzymatic Allergo-sorbent Test (Cap test Pharmacia). ${ }^{30,31}$

\section{Respiratory inflammation marker}

FeNO was determined with an on-line method using a single breath exhalation and a sensitive chemiluminescence assay (Ecomedics CLD 88), according to ATS-ERS. ${ }^{32}$ Patients made an inspiration of eNO-free air via a mouthpiece immediately followed by full exhalation at a constant rate $(50 \mathrm{ml} / \mathrm{sec})$ for at least 5 seconds. The mean of three readings at the end of the expiration 
(plateau phase) was taken as the representative value for each measurements. $12 \mathrm{ppb}$ or more were considered positive, according to ATS-ERS criteria. ${ }^{33}$

\section{Statistical analysis}

All values were expressed as Means and SD. Kruskal Wallis Test was performed for evaluating differences between the four groups (ObA, NwA, Ob, Nw). Statistical significance level was $\mathrm{p}<0.05$. Subsequently, differences within the single groups were tested by Mann-Whitney Test, adjusting the significance level by $\mathrm{p}<0.0125$. Differerences in functional respiratory parameters preand post-"free-run" exercise Challenge Test were analysed using Wilcoxon Signed Ranks Test within each group.

A multiple linear regression analysis was performed to asses the independent contribution of obesity (BMI-SDS) and asthma on respiratory inflammation and respiratory functional parameters. FeNO, PEF\% and MEF75\% were the dependent variables and BMI-SDS and asthma were the independent variables. Statistical significance level was $\mathrm{p}<0.05$.

All calculations were made with the computer program SPSS (Statistical Package for the Social Science), version 16.0 software for Windows. 


\section{RESULTS}

Anthropometric measurements and respiratory functional data are reported in table $\mathbf{1 .}$

The four groups were similar for age, gender, and height.

All the asthmatic children were allergic to Dermatophagoides Pteronyssinus (Df. pt).

As expected BMI and BMI-SDS was similar between obese asthmatic and obese non-asthmatic children, but was significantly different between obese and normal-weight children (ObA vs Ob: p $>0.05$; ObA vs NwA: $p=0.0004$; ObA vs Nw: $p=0.0008$; Ob vs NwA: $p=0.0001$; Ob vs Nw: $\mathrm{p}=0.0002)$.

\section{Baseline Respiratory Functional Parameters}

No significant differences were found for FVC\%, FEV1\%, MEF50\% and MEF25\% between the four groups.

Despite detecting a trend of difference in PEF\% between the four groups, no differences were found when performing sub-analysis between ObA vs NwA, ObA vs Ob, ObA vs Nw, NwA vs Ob, NwA vs $\mathrm{Nw}$, and $\mathrm{Ob}$ vs Nw.

We found that MEF75\% was significantly lower in OA group and OnA group compared to NnA group $(\mathrm{p}=0.004$ and $\mathrm{p}=0.0002$, respectively) (Table 1$)$.

Respiratory Functional Parameters after "free run” Exercise Challenge Test

No significant differences were found in FEV1\%, FVC\%, MEF50\% and MEF25\% after the exercise test among the four groups.

After the "free-run" exercise Challenge Test we found statistically significant differences in PEF\% and MEF75\%. In fact NnA had significantly higher values of these two parameters compared to OA $(\mathrm{p}=0.001$ for $\mathrm{PEF} \%$ and $\mathrm{p}=0.002$ for $\mathrm{MEF} 75 \%$ ); furthermore obese non-asthmatic children had significantly lower value of MEF75\% compared to the NnA group ( $\mathrm{p}=0.007)$ (Table 1). 
As shown in Table 2, analysing functional respiratory data within each group after the "free-run" exercise Challenge Test, we found that all analysed parameters, with the exception of FVC\% for the OA group and of MEF25\% for the NA group, decreased significantly in asthmatic obese and nonobese children (without clinical and functional evidence of obstruction - all indices were in the normal range for age and height). In contrast in non-asthmatic obese children we did not detect any statistical significant differences in all functional respiratory parameters after "free run" exercise Challenge Test.

\section{Respiratory inflammation marker}

FeNO values were significantly different across all four groups $(\mathrm{p}=0.0002)$.

In fact FeNO values were significantly higher in the ObA group compared to $\mathrm{Ob}$ group and to the Nw group ( $\mathrm{p}=0.011$ and $\mathrm{p}=0.0001$, respectively); and were significantly higher in the NwA group compared to $\mathrm{Ob}$ group and to the $\mathrm{Nw}$ group ( $\mathrm{p}=0.0002$ and $\mathrm{p}=0.0003$, respectively). We did not detect any statistical significant difference in FeNO values between the asthmatic children $(\mathrm{p}=0.201)$. Furthermore FeNO was significantly higher in the Ob group when compared to the Nw group $(\mathrm{p}=0.0004)$ (Figure 1).

Independent contribution of BMI-SDS and asthma on respiratory inflammation and respiratory functional parameters

In a multiple linear regression analysis with FeNO as the dependent variable and BMI-SDS and asthma (asthmatic vs non-asthmatic children) as the independent variables, asthma was significantly and independently related to FeNO values, whereas no association was found for obesity (BMISDS). In a second multiple linear regression model with PEF\% as the dependent variable and BMISDS and asthma as the independent variables, BMI-SDS was significantly and independently related to PEF\% values. A further multiple linear regression analysis with MEF75\% as the 
dependent variable and BMI-SDS and asthma as the independent variables, showed again that BMISDS was significantly and independently related to MEF75\% values (Table 3). 


\section{DISCUSSION}

This is the first study comparing obese asthmatic with obese non-asthmatic children and healthy controls with the aim to analyse the reciprocal influences of obesity and asthma on lung function in prepubertal children. Although the effect of obesity on pulmonary function tests has been extensively investigated in adults, the number of similar studies in children is limited and confirm the controversial results between obesity and AHR observed in adults.

In order to evaluate the relationship between obesity and AHR and to detect whether breathlessness experienced by obese children during physical activities is effectively due to the airway hyperresponsiveness we performed a "free-run" Exercise Challenge test. While basal values of spirometric indexes were normal in all examined groups, in asthmatic obese and non-obese children free run induced AHR documented by reduction of all functional respiratory parameters. In contrast in obese children no changes in these functional respiratory parameters were detected. In addition, in a multiple linear regression we found that asthma remained the only predictor for AHR. In agreement to our data, epidemiological studies do not uniformly support the conclusions that obesity leads to airflow limitation, AHR or asthma. In this respect Schachter and coworkers showed in a group of 1971 adults, that although BMI was associated with a clinical diagnosis of asthma and subjective symptoms of dyspnea and wheeze, airflow obstruction or AHR subsequent to histamine challenge could not be detected in the sole obese subjects. ${ }^{34}$ Similar findings were obtained by Bibi et al. ${ }^{35}$ who demonstrated in a large population of prepubertal children that broncodilation could not be induced by salbutamol inhalation in non-asthmatic obese subjects. ${ }^{36}$ These data demonstrate that obesity should not be considered as being a risk factor for AHR in prepubertal children. Furthermore asthma like symptoms especially during physical activity should not be overestimated by parents and medical staff. This is of paramount relevance as it might induce inappropriate treatment and refrain children from performing sports leading to a vicious circle impeding improvement of both obesity and respiratory symptoms. 
Interestingly in obese asthmatic children and obese non-asthmatic children we documented lower basal values of MEF75\% when compared to healthy controls. Furthermore by performing a multiple linear logistic regression analysis obesity, defined as BMI-SDS, was significantly and independently related to MEF75\%; while no association was found for asthma. Similar data were documented by two previous studies ${ }^{37,38}$ where obesity was associated with a significant reduction in $\mathrm{FEF}_{25-75}$. These data suggests that obesity might play a primary role on higher intrathoracic airway flows and despite being possibly explained by fatty infiltration of muscles narrowing directly the upper airway, recent literature suggest that this functional parameter might be used as an early predictor of subclinical asthma. In order to obtain a complete evaluation of bronchial status in this study we performed also FeNO analysis. In fact recent studies revealed that FeNO is a potentially useful measure to evaluate the role of airways inflammation in asthma, as it represents the forerunner of the most important event namely "remodelling" of bronchial airways. ${ }^{39}$ In fact FeNO, as recommended in the Consensus Report Practall for the Diagnosis, Management and Treatment of Childhood Asthma ${ }^{40}$ offers a logical complementary item to the only use of clinical and functional data, evaluating the bronchial eosinophilic inflammation. In our study, as expected, both groups of asthmatic children presented highly elevated FeNO values when compared to normal controls reflecting the underlying bronchial inflammation process. Data from animal and human studies clearly demonstrate that the enhancement of normal adipose tissue functions in obesity leads to a systemic proinflammatory state. ${ }^{41}$ Adipose tissue from obese individuals expresses a number of proinflammatory molecules, such as leptin, tumor necrosis factor- $\alpha$ (TNF- $\alpha$ ), IL-6, transforming growth factor- $\beta 1$ (TGF- $\beta 1$ ), and C-reactive protein (CRP), and there appears to be significant overlap between the immune function of adipocytes and the function of T-lymphocytes and macrophagues, particularly with respect to the elaboration of inflammatory cytokines. ${ }^{42,43}$ Although a conclusive relationship between obesity and airway inflammation has not yet to been described, it could be argued that the role of the proinflammatory state underlying the main metabolic and cardiovascular complications in obesity might play a pivotal role in determining airways 
inflammation independently of any allergic mechanisms. This might explain the findings of our study where FeNO values were significantly higher in obese non-asthmatic children compared to healthy controls and the findings of Santamaria et al. ${ }^{44}$ who found a positive correlation between FeNO and BMI in healthy children. However it needs to be acknowledged that in the multiple regression analysis obesity was not a predictor for increased FeNO values. This apparent contrasting findings might be partially explained by the age group of our study population as obesity related inflammation might not have reached its full implication and a possible involvement of the respiratory system might require a long standing history of obesity. As puberty is a well known risk factor for developing obesity related complications it might be of crucial interest to obtain longitudinal data starting in prepuberty and lasting through all pubertal stages in order to not underestimate the possible role of obesity on the development of bronchial inflammation and therefore to fully explore this intriguing relationship.

In conclusion, while AHR and airways inflammation are clearly associated to an asthmatic status, obesity seems to induce early proinflammatory airways changes combined with reduction of higher intrathoric airway flows. Longitudinal data are required in order to clarify whether these changes might represent risk factor for asthma later on in life.

\section{Acknowledgements}

We thank all nurses of the Department of Pediatrics, University of Chieti, in particular Di Santo D, Di Luca D, Diomedi A, for their daily support in clinical research and care of children. 


\section{REFERENCES}

1. Division of Health Examination Statistics, National Center for Health Statistics, Division of Nutrition and Physical Activity, National Center for Chronic Disease Prevention and Health Promotion, CDC Update. Prevalence of overweight among children, adolescents, and adults - United States, 1988-1994. MMWR 1997; 46: 199-202.

2. Mannino DM, Homa DM, Petrowski CA, Nixon LL, Johnson CA, Ball LB, Jack E, Kang DS. Surveillance for asthma - United States, 1960-1995. MMWR CDC Surveill Summ. 1998 Apr 24;47(1):1-27.

3. Woolcock AJ, Peat JK. Evidence for the increase of asthma worldwide. Ciba Found Symp 1997; 206: 122-34.

4. World Health Organization. Obesity: preventing and managing the global epidemic. WHO Technical Report Series 894. Geneva, Switzerland, WHO, 2000.

5. World Health Organization. Risk factors. World Health Report 2002. Geneva, Switzerland: WHO, 2002.

6. World Health Organization. Preventing chronic diseases: a vital investment. Geneva, Switzerland: WHO, 2005.

7. Figueroa-Munoz JI, Chinn S, Rona RJ. Association between obesity and asthma in 4-11 year old children in the UK. Thorax 2001; 56: 133-7.

8. Deane S, Thomson A. Obesity and the pulmonologist. Arch Dis Child 2006; 91: 188-191.

9. Power C, Lake JK, Cole TJ. Measurement and long term health risks of child and adolescent fatness. Int J Obes Relat Metab Disord 1997; 21: 507-526.

10. Schwartz J, Gold D, Dockery DW, Weiss ST, Speizer FE. Predictors of asthma and persistent wheeze in a national sample of children in U.S. Association with social class, perinatal events and race. Am Rev Respir Dis 1990; 142 (3): 555-562. 
11. Gennuso J, Epstein LH, Paluch RA, Cerny F. The relationship between asthma and obesity in urban minority children and adolescent. Arch Pediatr Adolesc Med 1998; 152 (12): 11971200.

12. Huang SL, Shiao G, Chou P. Association between body mass index and allergy in teenage girls in Taiwan. Clin Exp Allergy 1999; 29 (3): 323-329.

13. Busse WW, Lemanske RF Jr. Asthma. N Eng J Med 2001; 344: 350-2.

14. Gibson PG, Wlodarczyk JW, Hensley MJ, Gleeson M, Henry RL, Cripps AW, Clancy RL. Epidemiological association of airway inflammation with asthma symptoms and airway hyperresponsiveness in childhood. Am J Respir Crit Care Med 1998; 158: 36-41.

15. Payne DN, Adcock IM, Wilson NM, Oates T, Scallan M, Bush A. Relationship between exhaled nitric oxide and mucosal eosinophilic inflammation in children with difficult asthma, after treatment with oral prednisolone. Am J Respir Crit Care Med 2001; 164: 137681.

16. Visser M, Bouter LM, McQuillan GM, Wener MH, Harris TB. Elevated C-reactive protein levels in overweight and obese adults. JAMA 1999; 282: 2131-5.

17. Litonjua AA, Sparrow D, Celedon JC, DeMolles D, Weiss ST. Association of body mass index with the development of methacholine airway hyperresponsiveness in men: the Normative Aging Study. Thorax 2002; 57: 581-5.

18. Chinn S, Jarvis D, Burney P. Relation of bronchial responsiveness to body mass index in the ECRHS. European Community Respiratory Health Survey. Thorax 2002; 57: 1028-33.

19. Celedon JC, Palmer LJ, Litonjua AA, Weiss ST, Wang B, Fang Z, Xu X. Body mass index and asthma in adults in families of subjects with asthma in Anqing, China. Am J Respir Crit Care Med 2001; 164: 1835-40.

20. Kiess W, Reich A, Müller G, Galler A, Kapellen T, Raile K, Böttner A, Seidel B, Kratzsch J. Obesity in childhood and adolescence: clinical diagnosis and management. J Pediatr Endocrinol Metab. 2001;14 Suppl 6:1431-40. 
21. Dietz WH, Bellizzi MC. Introduction: the use of body mass index to assess obesity in children. Am J Clin Nutr. 1999 Jul;70(1):123S-5S.

22. http/www.ginasthma.it or www.ginasthma.org - GINA World Report 2006 - GLOBAL STRATEGY FOR ASTHMA MANAGEMENT AND PREVENTION.

23. National Asthma Education and Prevention Program. NAEPP expert panel report guidelines for the diagnosis and management of asthma - update on selected topics 2002. National Institutes for Health 2006.

24. Global Strategy for Asthma Management and Prevention, Global Initiative for Asthma (GINA) 2007. Available from: http://www.ginasthma.org.

25. Lindgren G, Strandell A, Cole T, Healy M, Tanner J. Swedish population standards for height, weight and body mass index attained at 6 to 16 years (girls) or 19 years (boy). Acta Pediatr 1995; 84: 1019-1028.

26. Laszlo G. Standardisation of lung function testing: helpful guidance from the ATS/ERS Task Force. Thorax. 2006 Sep; 61 (9): 744-6.

27. Crapo RO, Casaburi R, Coates AL, Enright PL, Hankinson JL, Irvin CG, MacIntyre NR, McKay RT, Wanger JS, Anderson SD, Cockcroft DW, Fish JE, Sterk PJ. Guidelines for Methacholine and Exercise Challenge Testing-1999. This official statements of the American Thoracic Society was adopted by the ATS Board of Directors, July 1999. Am J Respir Crit. Care Med 2000;161:309-329.

28. ATS Committee on Proficiency Standards for Clinical Pulmonary Function Laboratories. ATS statement: guidelines for the six-minute walk test. Am J Respir Crit Care Med 2002; 166: 111-117.

29. Godfrey S, Springer C, Bar-Yishay E, Avital A. Cut-off points defining normal and asthmatic bronchial reactivity to exercise and inhalation challenges in children and young adults. Eur Respir J. 1999; 14: 659-66. 
30. Terho E, Frew AJ et al., "Type III allergy skin testing. Position statement for EAACI Subcommittee on Skin Tests and Allergen Standardization”, Allergy, vol. 50, no. 5, pp. 3926, 1995.

31. Wolkerstorfer A, Wahn U, Kjellman NI, Diepgen TL, De Longueville M, Oranje AP, “Natural course of sensitization to cow's milk and hen's egg in childhood atopic dermatitis: ETAC Study Group”, Clinical \& Experimental Allergy, vol. 32, no. 1, pp. 70-73, 2002.

32. American Thoracic Society; European Respiratory Society. ATS/ERS recommendations for standardized procedures for the online and offline measurement of exhaled lower respiratory nitric oxide and nasal nitric oxide, 2005. Am J Respir Crit Care Med. 2005 Apr $15 ; 171(8): 912-30$.

33. Baraldi E, de Jongste JC; European Respiratory Society; American Thoracic Society. Measurement of exhaled nitric oxide in children, 2001. Eur Respir J 2002; 20 (1): 223-237.

34. Schachter LM, Salome CM, Peat JK, Woolcock AJ. Obesity is a risk for asthma and wheeze but not airway hyperresponsiveness. Thorax 2001;56:4-8.

35. Bibi H, Shoseyov D, Feigenbaum D, Genis M, Friger M, Peled R, Sharff S. The relationship between asthma and obesity in children: is it real or a case of over diagnosis? J Asthma 2004; 41 (4): 403-410.

36. Bibi H, Montgomery M, Paster kamp H, Chernick V. Relationship between response to inhaled salbutamol and methacholine bronchial provocation in children with suspected asthma. Pediatr Pulmonol 1991; 10: 244-248.

37. Spathopoulos D, Paraskakis E, Trypsianis G, Tsalkidis A, Arvanitidou V, Emporiadou M, Bouros D, Chatzimichael A. The effect of obesity on pulmonary lung function of school aged children in Greece. Pediatr Pulmonol 2009; 44: 273-280.

38. Ülger Z, Demir E, Tanaç R, Gökşen D, Gülen F, Darcan Ş, Can D, Coker M. The effect of childhood obesity on respiratory function tests and airway hyperresponsiveness. The Turkish Journal of Pediatrics 2006; 48: 43-50. 
39. van Veen IH, Sterk PJ, Schot R, Gauw SA, Rabe KF, Bel EH. Alveolar nitric oxide versus measures of peripheral airway dysfunction in severe asthma. Eur Respir J 2006; 27 (5): 951956.

40. Bacharier LB, Boner A, Carlsen K-H, Eigenmann PA, Frischer T, Götz M, Helms PJ, Hunt J, Liu A, Papadopoulos N, Platts-Mills T, Pohunek P, Simons FE, Valovirta E, Wahn U, Wildhaber J; European Pediatric Asthma Group. Diagnosis and treatment of asthma in childhood: a PRACTALL Consensus Report. Allergy 2008; 63: 5-34.

41. Fantuzzi G. Adipose tissue, adipokines, and inflammation. J Allergy Clin Immunol 2005; 115: 911-919.

42. Weisberg SP, McCann D, Desai M, Rosenbaum M, Leibel RL, Ferrante AW Jr. Obesity is associated with macrophage accumulation in adipose tissue. J Clin Invest 2003; 112: 17961808.

43. Wellen KE, Hotamisligil GS. Obesity-induced inflammatory changes in adipose tissue. J Clin Invest 2003; 112: 1785-1788.

44. Santamaria F, Montella S, De Stefano S, Sperlì F, Barbarano F, Valerio G. Relationship between exhaled nitric oxide and body mass index in children and adolescent. J Allergy Clin Immunol 2005; 116: 1163-1164. 
Table 1. Anthropometric measurements and respiratory parameters of the study population.

\begin{tabular}{|c|c|c|c|c|c|}
\hline & ObA & NwA & $\mathbf{O b}$ & Nw & $p^{\dagger}$ \\
\hline \multicolumn{6}{|c|}{ Clinical and Anthropometric characteristics } \\
\hline Gender $(M / F)$ & $16 / 14$ & $16 / 14$ & $14 / 16$ & $14 / 14$ & NS* \\
\hline \multirow[t]{2}{*}{ Age (years) } & 7.03 & 7.06 & 8.04 & 6.1 & NS \\
\hline & {$[6.05-8.02]$} & {$[6.77-8.05]$} & {$[7.05-9.02]$} & [6.03-8.09] & \\
\hline \multirow[t]{2}{*}{ Weight $(K g)$} & 35 & 25.75 & 42 & 24 & 0.0001 \\
\hline & {$[31-45.25]$} & {$[22-30.2]$} & {$[36.5-48]$} & {$[21-31.5]$} & \\
\hline \multirow{2}{*}{ SDS-Height } & 0.5 & 0.5 & 0.56 & 0.48 & NS \\
\hline & {$[0.06-1.2]$} & {$[0.05-1.1]$} & {$[0.05-1.55]$} & {$[0.051-1.2]$} & \\
\hline \multirow[t]{2}{*}{$S D S-B M I$} & 4.6 & 0.4 & 5 & $\mathbf{0}$ & 0.0001 \\
\hline & [3.85-5.45] & {$[-0.25-1.3]$} & {$[4.55-7.1]$} & {$[-0.4-0.1]$} & \\
\hline
\end{tabular}

\section{Respiratory inflammation marker}

$\boldsymbol{F e N O}(p p b)$

\section{Baseline Respiratory Functional Parameters}

$\boldsymbol{F V C}$ (Z-score)

FEV 1 (Z-score)

$\boldsymbol{F E} \boldsymbol{V}_{1} / \boldsymbol{F V C}$ (Z-score)

$\boldsymbol{F E F}_{25-75}$ (Z-score)

$\begin{array}{cc}\mathbf{- 0 . 2 6} & \mathbf{- 0 . 1 1} \\ {[-0.78-0.53]} & {[-0.48-0.33]} \\ \mathbf{- 0 . 1 4} & \mathbf{0 . 0 2 5} \\ {[-0.84-0.31]} & {[-0.35-0.44]} \\ \mathbf{0 . 1 1} & \mathbf{0 . 2 7} \\ {[-0.57-0.69]} & {[-0.58-1]} \\ \mathbf{- 0 . 1 3} & \mathbf{0 . 0 5}\end{array}$

$\mathbf{- 0 . 2 8}$

[-1.12-0.02]

0.12

[-0.74-0.73]

0.69

[-0.32-0.75]

$\begin{array}{cc}\mathbf{0 . 2 5} & \text { NS } \\ {[-0.76-1.99]} & \\ \mathbf{- 0 . 1 3} & \text { NS } \\ {[-0.66-2.01]} & \\ \mathbf{0 . 8 5} & \mathbf{0 . 0 2 5} \\ {[0.62-1.10]} & \\ \mathbf{0 . 4} & \text { NS } \\ {[0.08-0.56]} & \end{array}$

Respiratory Functional Parameters after "free run" Exercise Challenge Test

\begin{tabular}{|c|c|c|c|c|c|}
\hline \multirow[t]{2}{*}{ post-FEV 1 (Z-score) } & -0.97 & -1.11 & 0.09 & -0.03 & 0.009 \\
\hline & {$[-2.12-0.33]$} & {$[-1.60--0.37]$} & {$[-0.69-0.85]$} & {$[-1.57--0.03]$} & \\
\hline \multirow[t]{2}{*}{ post-FVC (Z-score) } & -1.01 & -1.15 & -0.43 & 0.20 & NS \\
\hline & {$[-1.71-0.31]$} & {$[-1.53--0.30]$} & {$[-1.15-0.36]$} & {$[-1.11-0.96]$} & \\
\hline \multirow[t]{2}{*}{ post-FE $V_{1} / \boldsymbol{F V} \boldsymbol{C}_{\text {(Z-score })}$} & -0.63 & 0.18 & 0.68 & 1.35 & 0.01 \\
\hline & {$[-1.12-0.48]$} & {$[-0.80-0.81]$} & {$[-0.14-1.95]$} & {$[-0.61-1.53]$} & \\
\hline \multirow[t]{2}{*}{ post-FEF $\boldsymbol{F}_{25-75}$ (Z-score) } & -0.22 & -0.06 & 0.3 & 0.42 & NS \\
\hline & {$[-0.65-0.13]$} & {$[-0.55-0.51]$} & {$[-0.21-0.49]$} & {$[-0.91-0.62]$} & \\
\hline \multirow[t]{2}{*}{ Fall in $F E V_{1}>12 \%$} & $5 / 30$ & $7 / 30$ & $2 / 30$ & $0 / 28$ & $0.008^{*}$ \\
\hline & $16.7 \%$ & $23.3 \%$ & $6.7 \%$ & $0 \%$ & \\
\hline
\end{tabular}

Values are Median [Interquartile Range]. NS, no significant difference $(P>0.05) . \mathrm{M}$, male; $\mathrm{F}$, female.

${ }^{\dagger}$ Kruskal Wallis Test

*Pearson's Chi-square $\left(\mathrm{X}^{2}\right)$ Test

BMI $=$ Body Mass Index;

$\mathrm{FVC}=$ Forced Vital Capacity; $\mathrm{FEV}_{1}=$ Forced Expiratory Volume in 1 sec; $\mathrm{FEV}_{1} / \mathrm{FVC}=$ Forced Expiratory Volume in 1 sec/ Forced Vital Capacity; $\mathrm{FEF}_{25-75}=$ Forced Expiratory Flows between $25 \%$ and $75 \%$ of the Forced Vital Capacity

All the tests are expressed as Z-score. 
Table 2. Comparison of the respiratory parameters after the 6MWT within each group.

\begin{tabular}{|c|c|c|c|c|c|}
\hline & & ObA & NwA & $\mathbf{O b}$ & Nw \\
\hline \multirow{2}{*}{\multicolumn{2}{|c|}{$\boldsymbol{F V C}$ (Z-score) }} & -0.26 & -0.11 & -0.28 & 0.25 \\
\hline & & {$[-0.78-0.53]$} & {$[-0.48-0.33]$} & {$[-1.12-0.02]$} & {$[-0.76-1.99]$} \\
\hline \multirow[t]{3}{*}{ post-FVC (Z-score) } & & -1.01 & -1.15 & -0.43 & 0.20 \\
\hline & & {$[-1.71-0.31]$} & {$[-1.53--0.30]$} & {$[-1.15-0.36]$} & {$[-1.11-0.96]$} \\
\hline & $\mathbf{p}^{\S}$ & NS & 0.0001 & NS & NS \\
\hline \multirow{2}{*}{$\boldsymbol{F E} \boldsymbol{V}_{1}$ (Z-score) } & & -0.14 & 0.025 & 0.12 & -0.13 \\
\hline & & {$[-0.84-0.31]$} & {$[-0.35-0.44]$} & {$[-0.74-0.73]$} & {$[-0.66-2.01]$} \\
\hline \multirow[t]{3}{*}{ post-FEV $V_{1}$ (Z-score) } & & -0.97 & -1.11 & 0.09 & -0.03 \\
\hline & & {$[-2.12-0.33]$} & {$[-1.60--0.37]$} & {$[-0.69-0.85]$} & {$[-0.75-2.46]$} \\
\hline & $\mathbf{p}^{\S}$ & NS & 0.0001 & NS & NS \\
\hline \multirow{2}{*}{\multicolumn{2}{|c|}{$\boldsymbol{F E} \boldsymbol{V}_{1} / \boldsymbol{F V C}$ (Z-score) }} & 0.11 & 0.27 & 0.69 & 0.85 \\
\hline & & {$[-0.57-0.69]$} & {$[-0.58-1]$} & {$[-0.37-1.45]$} & {$[0.62-1.10]$} \\
\hline \multirow{3}{*}{ post-FE $V_{1} / F \boldsymbol{V C}$ (Z-score) } & & -0.63 & 0.18 & 0.68 & 1.35 \\
\hline & & {$[-1.12-0.48]$} & {$[-0.80-0.81]$} & {$[-0.14-1.95]$} & {$[-0.61-1.53]$} \\
\hline & $\mathbf{p}^{\S}$ & 0.03 & NS & NS & NS \\
\hline \multirow{2}{*}{\multicolumn{2}{|c|}{$\boldsymbol{F E F}_{25-75}(Z$-score $)$}} & -0.13 & 0.05 & 0.35 & 0.4 \\
\hline & & {$[-0.49-0.25]$} & {$[-0.32-0.75]$} & {$[-0.30-0.93]$} & {$[0.08-0.56]$} \\
\hline \multirow[t]{3}{*}{ post-FEF $25-75$ (Z-score) } & & -0.22 & -0.06 & 0.3 & 0.42 \\
\hline & & {$[-0.65-0.13]$} & {$[-0.55-0.51]$} & {$[-0.21-0.49]$} & {$[-0.91-0.62]$} \\
\hline & $\mathbf{p}^{\S}$ & NS & 0.02 & NS & NS \\
\hline
\end{tabular}

Values are Median [Interquartile Range]. NS, no significant difference $(P>0.05)$.

${ }^{\S}$ Wilcoxon Signed Ranks Test

$\mathrm{FVC}=$ Forced Vital Capacity; $\mathrm{FEV}_{1}=$ Forced Expiratory Volume in $1 \mathrm{sec} ; \mathrm{FEV}_{1} / \mathrm{FVC}=$ Forced Expiratory Volume in 1 sec/ Forced Vital Capacity; $\mathrm{FEF}_{25-75}=$ Forced Expiratory Flows between $25 \%$ and $75 \%$ of the Forced Vital Capacity

All the tests are expressed as Z-scores. 
Table 3. Independent effect of asthma and obesity on lung function and bronchial inflammation.

\begin{tabular}{llccc}
\hline Source & Dependent Variable & Type III Sum of Squares & F & p $^{\#}$ \\
\hline Asthma & $F e N O$ & 655,174 & 3,957 & $\mathbf{0 . 0 4 8}$ \\
& $M E F_{75}(\%)$ & 505,481 & 1,038 & NS \\
& $P E F(\%)$ & 33,466 & 0,184 & NS \\
& $F E V_{1} / F V C(Z-$ score $)$ & 18,871 & 0,623 & NS \\
\hline Obesity & $F e N O$ & 119,116 & 0,719 & NS \\
& $M E F_{75}(\%)$ & 4156,102 & 8,534 & $\mathbf{0 . 0 0 5}$ \\
& $P E F(\%)$ & 1131,609 & 6,232 & $\mathbf{0 . 0 1 5}$ \\
& $F E V_{1} / F V C(Z-s c o r e)$ & 5,290 & 0,175 & NS \\
\hline
\end{tabular}

NS, no significant difference $(P>0.05)$.

${ }^{\#}$ Multiple analysis of covariance (MANCOVA)

$\mathrm{FeNO}=$ Fractional exhaled Nitric Oxide; $\mathrm{MEF}_{75}=$ Maximal Expiratory Flow at $75 \%$ of the Forced Vital Capacity; PEF $=$ Peak Expiratory Flow; $\mathrm{FEV}_{1} / \mathrm{FVC}=$ Forced Expiratory Volume in $1 \mathrm{sec} /$ Forced Vital Capacity

$\mathrm{FEV}_{1} / \mathrm{FVC}$ ratio are expressed as $\mathrm{Z}$-score.

$\mathrm{MEF}_{75}$ and PEF are expressed as percentage of theoretical values for age, gender, and height. 


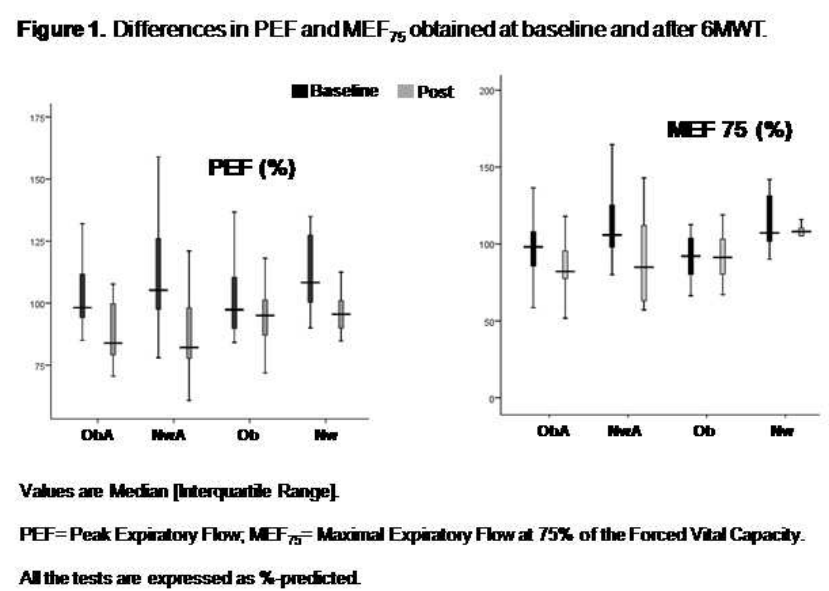

$254 \times 190 \mathrm{~mm}(96 \times 96 \mathrm{DPI})$

John Wiley \& Sons, Inc. 


\section{UNIVERSITY OF CHIETI}

- ITALY -

www.unich.it/cliped/

\section{Pediatric Department}

(Chief: Prof. Francesco Chiarelli)

Dear Editor,

Thank you for giving us the possibility of revising and resubmitting our manuscript PPUL-09-0317 entitled "The reciprocal influences of asthma and obesity on lung function testing, AHR and airway inflammation in prepubertal children."

We thank you and the referees for the detailed review and for the precious comments, which we have addressed thoroughly thereby improving our manuscript substantially.

We have tried to answer the major comments of referee 1 and 2 and please find enclosed a point-bypoint answer sheet for each of them.

In agreement with your suggestion we have now calculated and expressed the results of the lung function tests as Z-score, according to the equations proposed by Stanojevic et al. (AJRCCM 2008). However, we continue to present the values of $\mathrm{MEF}_{75}$ and PEF as \%-expected because for these parameters the equations for Z-score were not available and the main differences detected in our study regarded these indices of lung function.

Furthermore, as requested we added all necessary information concerning our inclusion and exclusion criteria in the method section. We have modified the introduction in order to define in a clear way the main hypothesis of our study. Finally the most important limitation consisting of the cross sectional nature of this study has been discussed.

Please find enclosed the revised version of our manuscript where the changes have been marked-up. We hope that our findings on this intriguing relationship between obesity and asthma are of interest to your readership and hope that the manuscript is now acceptable for publication in your prestigious journal.

Do not hesitate to contact us should further changes be necessary

Yours Sincerely,

Angelika Mohn

Department of Pediatrics

University of Chieti

Ospedale Policlinico

Via dei Vestini 5

66100 Chieti, Italy

Fax: +39 0871-574831

E-mail: amohn@unich.it 